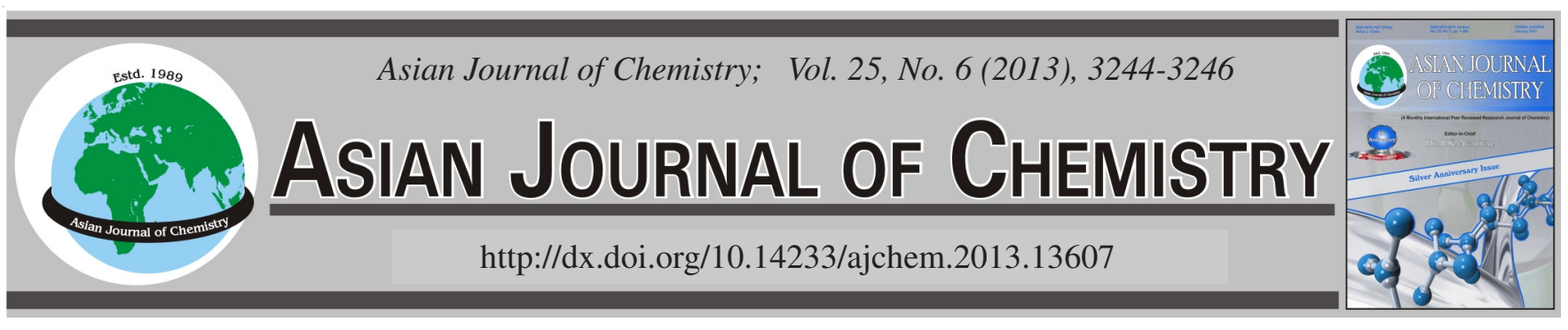

\title{
Amino Acids Catalyzed Biginelli Protocols
}

\author{
Ansa Madeeha Zafar ${ }^{1}$, Saira Qureshi ${ }^{2}$, Muhammad Naeem Khan ${ }^{3}$, \\ Muhammad Azad ${ }^{4}$, Munawar Ali Munawar ${ }^{2}$ and Misbahul Ain Khan ${ }^{1,2, *}$
}

\begin{abstract}
${ }^{1}$ Department of Chemistry, The Islamia University of Bahawalpur, Bahawalpur, Pakistan ${ }^{2}$ Institute of Chemistry, University of the Punjab, Quaid-e-Azam Campus, Lahore, Pakistan ${ }^{3}$ Applied Chemistry Research Centre, PCSIR Laboratories Complex, Lahore, Pakistan ${ }^{4}$ Government Polytechnic Institute for Printing and Graphic Arts, Lahore, Pakistan
\end{abstract}

*Corresponding author: E-mail: misbahakhan@gmail.com

(Received: 16 February 2012;

Accepted: 14 December 2012)

AJC-12557

Various amino acids were found to be excellent catalysts for the Biginelli dihydropyimidone synthesis. The method is simple and provides an alternate and efficient catalyst for the multiple component reactions.

Key Words: Dihydropyrimidones, Amino acids, Multiple component reactions.

\section{INTRODUCTION}

The three component Biginelli reaction (Scheme-I) is gaining much attention due to its versatility and its inherent scope for providing scaffolds for further synthetic work. The ready availability of potential biologically active molecules also adds to its popularity and the attention it is getting from chemists ${ }^{1}$. The synthesis involving diverse catalysts e.g., metal salts $^{2}$, Bronsted and Lewis acids ${ }^{3}$ to the application of microwave irradiation ${ }^{4}$ and other solvent-free synthetic processes ${ }^{5}$ have been reported. Due to our continuous interest in the synthesis of heterocyclic compounds, the Biginelli reaction is of interest for the synthesis of pyrimidine based systems and an effort is now directed towards developing new catalysts for these and related syntheses.

Although some trans-4-hydroxyproline-derived secondary amines together with Bronsted acids have been reported for an enantioselective Biginelli reaction ${ }^{6}$, to our best of knowledge, there is a scant literature reference employing amino acids as catalysts for this multicomponent important reaction.
Another study using L-proline methyl ester for the synthesis of dihydropyrimidone has also been published ${ }^{7}$. Recently the catalytic use of L-proline was described for the synthesis of pyrano[2,3-d]pyrimidines ${ }^{8}$ which has prompted us to communicate the results of our work of amino acids as catalysts in this reaction. Here we will be reporting the synthesis of 5-ethoxycarbonyl-6-methyl-4-phenyl-3,4-dihydropyrimidin2-one (I) and 2-thione (II) in the presence of various amino acids. However work utilizing other 1,3-dicarbonyl compounds and aldehydes is being continued.

\section{EXPERIMENTAL}

The IR spectra were taken on Perkin Elmer spectrum BX 1. The ${ }^{1} \mathrm{H}$ NMR spectra were obtained on a Bruker $300 \mathrm{MHz}$ spectrometer using DMSO- $d_{6}$ as the solvent and TMS as an internal standard. Melting points were determined on a Galenkamp apparatus and are uncorrected. All the chemicals and amino acids used in the present work were commercial products of Fluka, Aldrich or Merck and were used without<smiles></smiles>

Scheme-I<smiles>[X]C1=NC(c2ccccc2)C(C(=O)OCC)=C(C)N1</smiles>

I X= O, II X=S 
further purification. The progress of the reaction was monitored by TLC.

\section{General procedure}

Synthesis of 5-ethoxycarbonyl-6-methyl-4-phenyl-3,4dihydropyrimidin-2-one (I) and 2-thione (II): A mixture of benzaldehyde ( $4.2 \mathrm{~g}, 40 \mathrm{mmol})$, ethyl acetoacetate $(5.2 \mathrm{~g}, 40$ $\mathrm{mmol}$ ), urea (or thiourea) $45 \mathrm{mmol}$, an amino acid $(0.01 \mathrm{mmol})$ and $10 \mathrm{~mL}$ of ethanol was heated under reflux (or stirred at room temperature). After cooling, the reaction mixture was diluted with water and the precipitated product was filtered, washed with water, dried and recrystallized from ethanol.

I: m.p. $196{ }^{\circ} \mathrm{C}$, Lit. $202^{\circ} \mathrm{C}^{12}$, IR (KBr, $\left.\mathrm{n}_{\max }, \mathrm{cm}^{-1}\right): 3239$, 3110, 1725, 1702, 1646. ${ }^{1} \mathrm{H}$ NMR (DMSO): $\delta: 1.06(3 \mathrm{H}, \mathrm{t}, J=$ $7.2 \mathrm{~Hz}), 2.23(3 \mathrm{H}, \mathrm{s}), 3.98(2 \mathrm{H}, \mathrm{q}, J=7.2 \mathrm{~Hz}), 5.12(1 \mathrm{H}, \mathrm{s})$, 7.21-7.32 (5H, m), $7.60(1 \mathrm{H}, \mathrm{s}), 9.14(1 \mathrm{H}, \mathrm{s})$.

II: m.p. $196{ }^{\circ} \mathrm{C}$, Lit. ${ }^{12} 205-206^{\circ} \mathrm{C}$, IR $\left(\mathrm{KBr}, v_{\max }, \mathrm{cm}^{-1}\right)$ : 3234, 3104, 1729, 1639, 1225.

\section{RESULTS AND DISCUSSION}

The classical Biginelli reaction is usually conducted in ethanol with an acid catalyst such as hydrochloric acid. In the present work, the reactions were conducted in ethanol solvent in the presence of catalytic amounts of different amino acids. The effect of amino acid, its quantity, time and temperature of the reactions were also studied to compare these parameters' influence on the yields of the product I. Equivalent amounts of the three components were used with a little excess of urea/ thiourea. Glycine was used for all the experiments.

Amount of catalyst: Initially $10 \mathrm{mmol}$ of glycine was used for the $40 \mathrm{mmol}$ quantities of the reactants and I was obtained in $74 \%$ yield. Diminishing the quantities of glycine showed that a very small amount $0.01 \mathrm{mmol}$ was sufficient for a comparable yield without compromising the purity of the product. The results are given in Table-3.

Reaction time and temperature: The trial reactions were conducted both at room temperature $\left(30^{\circ} \mathrm{C}\right)$ and at reflux in ethanol $\left(80^{\circ} \mathrm{C}\right)($ Table-4). It was observed that $4 \mathrm{~h}$ refluxing gave better yield $(90 \%)$ while without heating (mere stirring at the room temperature for $12 \mathrm{~h}$ ) presented the product in $74 \%$ yield. In both the cases (reflux or room temperature) prolonged periods of reaction were detrimental to the yields and the purity of the product. The products obtained were darker in colour perhaps due to some decomposition.

The results of Tables 1-4 are evidently indicative of the usefulness of amino acids as alternatives in Biginelli reaction. The yields and the purity of the compounds from these reactions, the small quantity of the catalyst required for the reaction and the non-toxicity of the amino acids make it the catalyst of choice. Although a few amino acids are being reported but the scope can be extended to include other amino acids.

The role of the amino acid in these condensations appears to be two fold and fits in well with the mechanism proposed earlier by Folkers and Johnson ${ }^{9}$ and Kappe ${ }^{10}$ (Scheme-II). In the initial condensation step of urea with the aldehyde to give the adduct, the amino acid aids in this acid catalyzed reaction while in the following step, the amino acid functioning as a base effects the nucleophilic addition of the $\mathrm{CH}$ compound finally effecting the ring closure.

\begin{tabular}{|c|c|c|}
\hline \multicolumn{3}{|c|}{$\begin{array}{c}\text { TABLE-1 } \\
\text { AMINO ACID CATALYZED SYNTHESIS OF } \\
\text { 5-ETHOXYCARBONYL-6-METHYL-4-PHENYL- } \\
\text { 3,4-DIHYDROPYRIMIDIN-2-ONE }(\mathbf{I}, \mathrm{X}=\mathrm{O})\end{array}$} \\
\hline Amino acid & Yield (\%) & m.p. $\left({ }^{\circ} \mathrm{C}\right)^{*}$ \\
\hline Glycine & 87 & 196 \\
\hline Hippuric acid & 68 & 196 \\
\hline Glutamic acid & 74 & 195 \\
\hline L. leucine & 68 & 194 \\
\hline Tryptophan & 83 & 196 \\
\hline Histidine & 83 & 196 \\
\hline
\end{tabular}

\section{TABLE-2}

AMINO ACID CATALYZED SYNTHESIS OF 5-ETHOXYCARBONYL-6-METHYL-4-PHENYL3,4-DIHYDROPYRIMIDIN-2-THIONE (II, X = S)

\begin{tabular}{lcc}
\hline \multicolumn{1}{c}{ Amino acid } & Yield $(\%)$ & m.p. $\left({ }^{\circ} \mathrm{C}\right)^{*}$ \\
\hline Glycine & 74 & 196 \\
Hippuric acid & 71 & 196 \\
Glutamic acid & 81 & 195 \\
L. leucine & 77 & 195 \\
Tryptophan & 72 & 196 \\
Histidine & 69 & 196
\end{tabular}

*Lit. m.p. $205-206^{\circ} \mathrm{C}^{12}$.<smiles>O=Cc1ccccc1</smiles><smiles>[O+]=Cc1ccccc1</smiles><smiles>[X]C(=C)N</smiles><smiles>[X]/C(N)=[NH+]/C(=C/C=C/C(=O)OCC)C(C(C)=O)C(NC(=[X])N)c1ccccc1</smiles><smiles>[X]C1=NC(c2ccccc2)C(C(=O)OCC)=C(C)N1</smiles>

Scheme-II 


\begin{tabular}{|c|c|c|c|c|}
\hline \multicolumn{5}{|c|}{$\begin{array}{c}\text { TABLE-3 } \\
\text { YIELD OF DHPM (I) VERSUS THE AMOUNT } \\
\text { OF CATALYST (GLYCINE) USED }\end{array}$} \\
\hline \multicolumn{2}{|c|}{ Amount of glycine (mmol) } & \multicolumn{2}{|c|}{ Yield $(\%)$} & m.p. $\left({ }^{\circ} \mathrm{C}\right)^{*}$ \\
\hline \multicolumn{2}{|c|}{10} & \multicolumn{2}{|c|}{74} & 196 \\
\hline \multicolumn{2}{|c|}{1} & \multicolumn{2}{|c|}{79} & 194 \\
\hline \multicolumn{2}{|c|}{0.1} & \multicolumn{2}{|c|}{87} & 198 \\
\hline \multirow{2}{*}{\multicolumn{5}{|c|}{$\frac{0.01}{{ }^{*} \text { Lit. m.p. } 205-206^{\circ} \mathrm{C}^{12}}$}} \\
\hline & & & & \\
\hline \multicolumn{5}{|c|}{$\begin{array}{c}\text { TABLE-4 } \\
\text { EFFECT OF TEMPERATURE AND TIME ON THE } \\
\text { YIELD OF DHPM (I) (GLYCINE CATALYST) } \\
\end{array}$} \\
\hline Entry & Temp. $\left({ }^{\circ} \mathrm{C}\right)$ & Time (h) & Yield (\%) & m.p. $\left({ }^{\circ} \mathrm{C}\right)^{*}$ \\
\hline 1 & RT & 3 & 55 & 192 \\
\hline 2 & - & 6 & 60 & 196 \\
\hline 3 & - & 9 & 69 & 195 \\
\hline 4 & - & 12 & 74 & 196 \\
\hline 5 & - & 24 & 66 & 196 \\
\hline 6 & 80 & 2 & 84 & 194 \\
\hline 7 & - & 4 & 90 & 196 \\
\hline 8 & - & 6 & 81 & 195 \\
\hline 9 & - & 8 & 70 & 196 \\
\hline
\end{tabular}

The role of the amino acid in the modified Knoevenagel reaction has been described in the literature ${ }^{11}$ which could possibly also be supportive for its likewise action in the Biginelli synthesis. An alternate mechanistic way via an enamine $^{7}$ can also not be ruled out.

\section{Conclusion}

Based on the results of the present investigations it seems that amino acids can be used as effective catalyst for the multiple component reactions. The method is safe, simple and the yields are comparable to the other catalysts.

\section{ACKNOWLEDGEMENTS}

The authors are grateful to Higher Education Commission, Govt. of Pakistan for a scholarship to Ansa Madeeha Zafar.

\section{REFERENCES}

1. C.O. Kappa and A. Stadler, Org. React., 63, 1 (2004); C.O. Kappe, Eur. J. Med. Chem., 35, 1043 (2000).

2. J. Lu and H. Ma, Synlett, 63 (2000); J. Lu and Y.-H. Bai, Synthesis, 466 (2002); J. Lu, Y.-H. Bai, Y.-H. Guo, Z.-J. Wang and H.-R. Ma, Chin. J. Chem., 20, 681 (2002); R. Fazaeli, S. Tangestaninejad and H. Aliyan, Asian J. Chem., 22, 877 (2010); B.C. Ranu, A. Hajra and U. Jana, J. Org. Chem., 65, 6270 (2000); N.-Y. Fu, Y.-F. Yuan, Z. Cao, S.W. Wang,
J.-T. Wang and C. Peppe, Tetrahedron, 58, 4801 (2002); Y.-F. Yuan, M.L. Pang, J.-T. Wang and C. Peppe, J. Organomet. Chem., 672, 52 (2003); Ch-V. Reddy, M. Mahesh, P.V.K. Raju, T.R. Babu and V.N.N. Reddy, Tetrahedron Lett., 43, 2657 (2002); J. Lu, Y.-H. Bay, Z.-J. Wang, B. Yang and H. Ma, Tetrahedron Lett., 41, 9075 (2000); D.S. Bose, L. Fatima and H.B. Mereyala, J. Org. Chem., 68, 587 (2003); D. Russowsky, F.A. Lopes, V.S.S. da Silva, K.F.S. Canto, M.G.M. D'oca and M.N. Godoi, J. Braz. Chem. Soc., 15, 165 (2004); U.B. More, Asian J. Chem., 24, 1906 (2012).

3. A. Hajra and U. Jana, J. Org. Chem., 65, 6270 (2000); Z.T. Wang, L.W. Xu and H.Q. Wang, Tetrahedron Lett., 45, 7951 (2004); J. Lu, Y. Bai, Z. Wang, B. Yang and H. Ma, Tetrahedron Lett., 41, 9075 (2000); S.K. De and R. A. Gibbs, Synthesis, 1748 (2005); S.V. Ryabukhin, A.S. Plaskon, E.N. Ostapchuk, D.M. Volochnyuk and A.A. Tolmachev, Synthesis, 417 (2007); J.H. Schauble, E.A. Trauffer, P.P. Deshpande and R.D. Evans, Synthesis, 1333 (2005); J. Lu and H.R. Ma, Synlett, 63 (2000); E.H. Hu, D.R. Sidler and U.H. Dolling, J. Org. Chem., 63, 3454 (1998); Y.Yu, D. Liu and G. Luo, Bioorg. Med. Chem. Lett., 17, 3508 (2007).

4. H. Hazarkhani and B. Karimi, Synthesis, 1239 (2004); A. Stadler and C.O. Kappe, J. Chem. Soc. Perkin Trans. I, 1363 (2000); H.A. Stefani and P.M. Gatti, Synth. Commun., 30, 2165 (2000); C.O. Kappe, D. Kumar and R.S. Varma, Synthesis, 1799 (1999); J.J.V. Eynde and A. Mayenee, Molecules, 8, 381 (2003); A. Stadler, B.H. Yonsefi, W.P. Dallinger, E. Vander Eycken, N. Kaval and C.O. Kappe, Org. Process Res. Dev., 7, 707 (2003); A. Stadler and C.O. Kappe, J. Comb. Chem., 3, 624 (2001); M. Rahman, J. Heterocycl. Chem., 47, 1230 (2010).

5. J.H. Schauble, E.A. Trauffer, P.P. Deshpande and R.D. Evans, Synthesis, 1333 (2005); S.K. De and R.A. Gibbs, Synthesis, 1748 (2005); M. Abdollahi-Alibeik abd Zaghghi, Chem. Papers, 63, 97 (2009); T. Boumoud, B. Boumoud, S. Rhouati, A. Belfaitah, A. Debache and P. Mosset, Acta Chim. Slov., 55, 617 (2008); D. Song, R. Wang, Y. Chen, S. Zhang, C. Liu and G. Luo, React. Kinet. Catal. Lett., 95, 385 (2008); A. Debache, R. Boulcina, T. Radia, A. Belfaitah, S. Rhouati and B. Carboni, Chin. J. Chem., 26, 2112 (2008); M. Nasr-Esfahani, B. Karami, M. Montazerozohori and A. Karim, J. Heterocycl. Chem., 45, 1183 (2008); H. Valizadeh, H. Gholipur, R. Zarrebin, M. Amir, M.R. Sabzi, Phosphorous Sulfur Silicon Rel. Elem., 183, 1552 (2008); N. Pai, K. Waghmode and D. Khandekar, Asian J. Chem., 23, 5217 (2011); B. Mirza, M. Sargordan and R. Fazaeli, Asian J. Chem., 24, 1421 (2012).

6. J. Xin, L. Chang, Z. Hou, D. Shang, X. Liu and X. Feng, Chem. Eur. J., 14, 3177 (2008).

7. J. Mabry and B. Ganem, Tetrahedron Lett., 47, 55 (2006).

8. M. Bararjanian, S. Balalaie, B. Morassagh and A.M. Amani, Iran. J. Chem., 6, 436 (2009).

9. K. Folkers and T.B. Johnson, J. Am. Chem. Soc., 55, 3784 (1933).

10. C.O. Kappe, J. Org. Chem., 62, 7201 (1997).

11. H.D. Dakin, J. Biol. Chem., 7, 49 (1909); C.A.C. Haley and P. Maitland, J. Chem. Soc., 3155 (1951); F.S. Prout, J. Org. Chem., 18, 928 (1953); J. Diekmann, W.R. Hertler and R. Benson, J. Org. Chem., 28, 2719 (1963); D.B. Ramchary, N.S. Chowdari and C.F. Barbas III, Angew. Chem. Int. Ed., 42, 4233 (2003); Y. Wang, Z.-C. Shang, T.-X. Wu, J.C. Fan and X. Chen, J. Mol. Catal. A, Chem., 253, 212 (2006).

12. K. Folkers, H.J. Harwood and T.B. Johnson, J. Am. Chem. Soc., 54, 3751 (1932). 